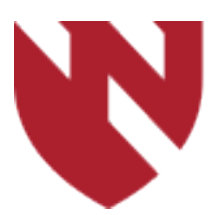

September 2020

\title{
Improving Clinical Performance and Quality Measures Following Acute Myocardial Infarction
}

\author{
Sajid Kadir \\ University of Nebraska Medical Center \\ Vasa Jacob \\ University of Nebraska Medical Center \\ Evan Ryan \\ University of Nebraska Medical Center \\ Rahul Dhawan \\ University of Nebraska Medical Center \\ Cason Christensen \\ University of Nebraska Medical Center
}

See next page for additional authors

Tell us how you used this information in this short survey.

Follow this and additional works at: https://digitalcommons.unmc.edu/gmerj

Part of the Higher Education Commons, and the Medicine and Health Sciences Commons

\section{Recommended Citation}

Kadir, S., Jacob, V., Ryan, E., Dhawan, R., Christensen, C., , O'Leary, E. Improving Clinical Performance and Quality Measures Following Acute Myocardial Infarction. Graduate Medical Education Research Journal. 2020 Sep 29; 2(1).

https://digitalcommons.unmc.edu/gmerj/vol2/iss1/79

This Conference Proceeding is brought to you for free and open access by DigitalCommons@UNMC. It has been accepted for inclusion in Graduate Medical Education Research Journal by an authorized editor of DigitalCommons@UNMC.For more information, please contact digitalcommons@unmc.edu. 


\section{Improving Clinical Performance and Quality Measures Following Acute Myocardial Infarction}

\section{Creative Commons License}

\section{(c) (1) $\Theta(9$}

This work is licensed under a Creative Commons Attribution-Noncommercial-No Derivative Works 4.0 License.

\section{Authors}

Sajid Kadir, Vasa Jacob, Evan Ryan, Rahul Dhawan, Cason Christensen, and Edward O'Leary 
The Weights Felt Heavier Today...

Jordan C. Rennicke ${ }^{1}$, Rebecca L. Peebles ${ }^{1}$

${ }^{1}$ University of Nebraska Medical Center, Department of Family Medicine and Offutt Airforce Base Family Medicine Residency, Offutt Airforce Base, NE

Mentor: Rebecca L Peebles

Program: Family Medicine

Type: Case Report

Background: Cervical radiculopathy can occur across all activity levels. It is most common in ages 50-54 and in the C6-C7 nerve roots. It is a clinical diagnosis that commonly resolves with non-operative management, but imaging and surgical intervention are sometimes indicated.

Methods: Physical exam, EMG, X-Ray, MRI.

Results: A 52 year-old male weightlifter presents with 1.5 years of left elbow pain. Symptoms were insidious, but acutely worsened after feeling a sharp pain while bench pressing. He rested for several months but, when he resumed bench pressing, noticed decreased strength and range of motion with elbow extension. He subsequently completed a full course of physical therapy, relieving his pain entirely, but presents to Sports Medicine for persistent weakness. Patient notes triceps atrophy compared to his right but denies bruising, swelling, numbness, or tingling. Pertinent exam findings include triceps insertion tenderness and $4 / 5$ elbow extension strength. Workup revealed a moderate olecranon enthesophyte on elbow x-ray and changes consistent with triceps tendinopathy and possible proximal radial nerve entrapment on limited ultrasound. EMG was suggestive of left C7 radiculopathy and MRI C-spine confirmed multilevel degenerative changes with foraminal narrowing greatest at C6-C7. After discovery of the $\mathrm{C} 7$ radiculopathy, the patient was referred to neurosurgery, but no intervention was ultimately performed.

Conclusion: The initial exam was consistent with triceps tendinopathy. Treatment was tailored accordingly but the problem persisted. Subsequently, C7 radiculopathy was found to be the true etiology of triceps pathology. Expanding the differential is paramount when a patient is not improving and consideration of proximal etiologies is crucial to explain distal injuries.

https://doi.org/10.32873/unmc.dc.gmerj.2.1.076

\section{Improving Clinical Performance and Quality Measures Following Acute Myocardial Infarction \\ Sajid Kadir1, Vasa Jacob", Evan Ryan¹, Rahul Dhawan', Cason Christensen', Edward O'Leary \\ 1 University of Nebraska Medical Center, Department of Cardiology}

Mentor: Edward O'Leary

Program: Cardiology

Type: Original Research

Background: ACC/AHA has set clinical performance measures (CPM) and quality measures $(\mathrm{QM})$ for the care of acute myocardial infarction (AMI) patients during their index hospitalization. Despite these criteria, standards are not consistently met in real-world practice. The aim of this project is to improve our institution's compliance with the national performance and quality metrics.

Methods: Retrospective data analysis of AMI patients was completed at our institute for a data more than three months specifically measuring baseline standards met for CPM and QM. Following this, a checklist was implemented to be utilized in the process of discharging every AMI patient. This checklist was distributed in the form of laminated cards to physicians (Figure 1A) involved in direct patient care, coupled with monthly provider meetings to encourage checklist use. Postintervention, the standards met for CPM and QM will be measured again to assess for interval change.

Results: Pre-intervention CPM regarding aspirin and beta-blocker use at discharge were met in $100 \%$ of cases. CPM for high-intensity statin and $\mathrm{P} 2 \mathrm{Y} 12$ receptor inhibitors were $98 \%$ and $90 \%$, respectively. Evaluation of left ventricular function was completed in $93 \%$ and cardiac rehabilitation facility referral was done in $97 \%$. QM of aldosterone antagonist prescription at discharge was met in $87 \%$ cases (Figure 1B).

\begin{tabular}{ll}
\multicolumn{1}{c}{$\begin{array}{c}\text { AMI Checklist (STEMI/NSTEMI) } \\
\text { Discharge Measures } \\
\text { (if not ordered-document why contraindicated) }\end{array}$} & Recommended Medication Choices \\
\hline$\square$ ASA & High Dose Statin: \\
\hline$\square$ High Intensity Statin & Atorvastatin 40-80mg once daily \\
\hline$\square$ Beta Blocker & Rosuvastatin 20-40mg once daily \\
\hline$\square$ Aldosterone Antagonist (EF <35\%) & Beta Blockers: \\
\hline$\square$ ACE/ARB (EF <40\%) & Extended Release Metoprolol \\
\hline$\square$ LV Function Evaluation (ECHO) & Carvedilol \\
\hline$\square$ Tobacco Cessation & Bisoprolol \\
\hline$\square$ Outpt Cardiac Rehab Referral & \\
\hline$\square$ DAPT & \\
\hline
\end{tabular}

Figure 1A. Checklist distributed to physicians.

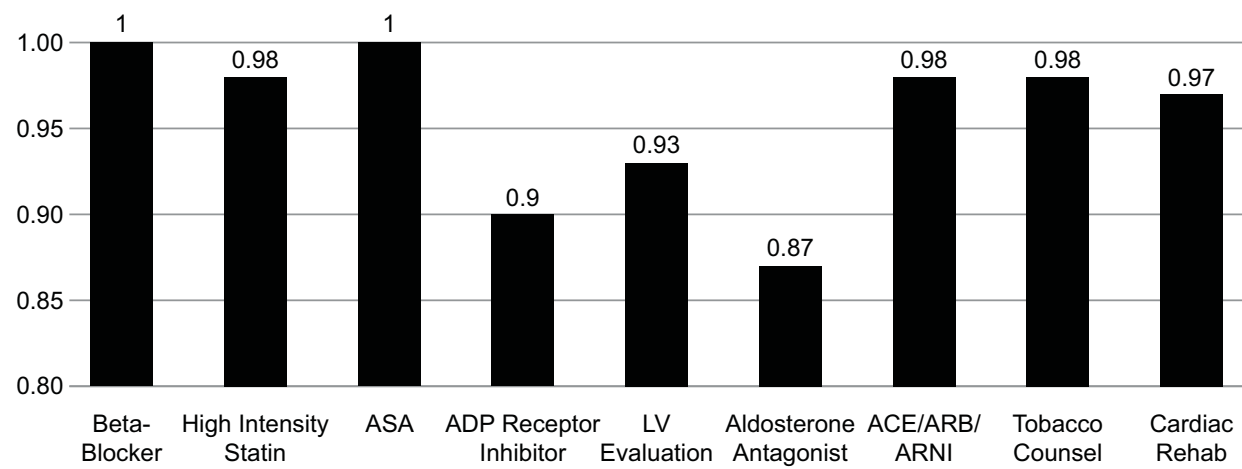

Figure 1B. Standard met for checklist items. 
Conclusion: CPM and QM set by ACC/AHA are not always met during care of post-AMI patients. One common barrier is documenting contraindications to recommended therapies. Quality improvement projects should be implemented to optimize the rate of CPM and QM met.

https://doi.org/10.32873/unmc.dc.gmerj.2.1.058

\section{Right Ventricular Lead Dysfunction Post LVAD Implantation}

Ahmed Mohamed Abdelhalim-Selim¹, Rahul Dhawan', Katheine Germann¹, Scott Lundgren'1, Ronald Zolty ${ }^{1}$, Faris Khan ${ }^{1}$

${ }^{1}$ University of Nebraska Medical Center, Department of Internal Medicine, Division of Cardiovascular Disease

\section{Mentor: Faris Khan}

Program: Internal Medicine, Division of Cardiovascular Disease

Type: Original Research

Background: The use of left ventricular assist devices (LVAD), both as bridge to cardiac transplantation as well as destination therapy, has increased significantly over the last few years. The vast majority of these patients are eligible for electrical implantable devices (including single, dual chamber, and biventricular defibrillators). There is scarcity of data on the impact of LVAD placement on the right ventricular lead integrity in these devices

Methods: We studied a total of 50 patients who had implantable cardioverter device (single, dual chamber and biventricular device) prior to LVAD placement at the University of Nebraska between 2017 and 2019, a chart review was done to identify patients with right ventricular lead dysfunction that was diagnosed post LVAD implantation.

Results: The mean age of patients at the time of LVAD was $54(+/-14)$ years, the study included 41 males $(82 \%)$. Forty-two patients had Heartmate III, four had Heartmate II and four patients had Heartware LVAD.
Twenty seven patients had single or dual chamber ICD (54\%) while 23 patients had a biventricular ICD (46\%). Right ventricular lead malfunction was reported in 18 patients (36\%) within 6 months of LVAD implantation. The type of left ventricular assist devices and electrical devices were not significantly

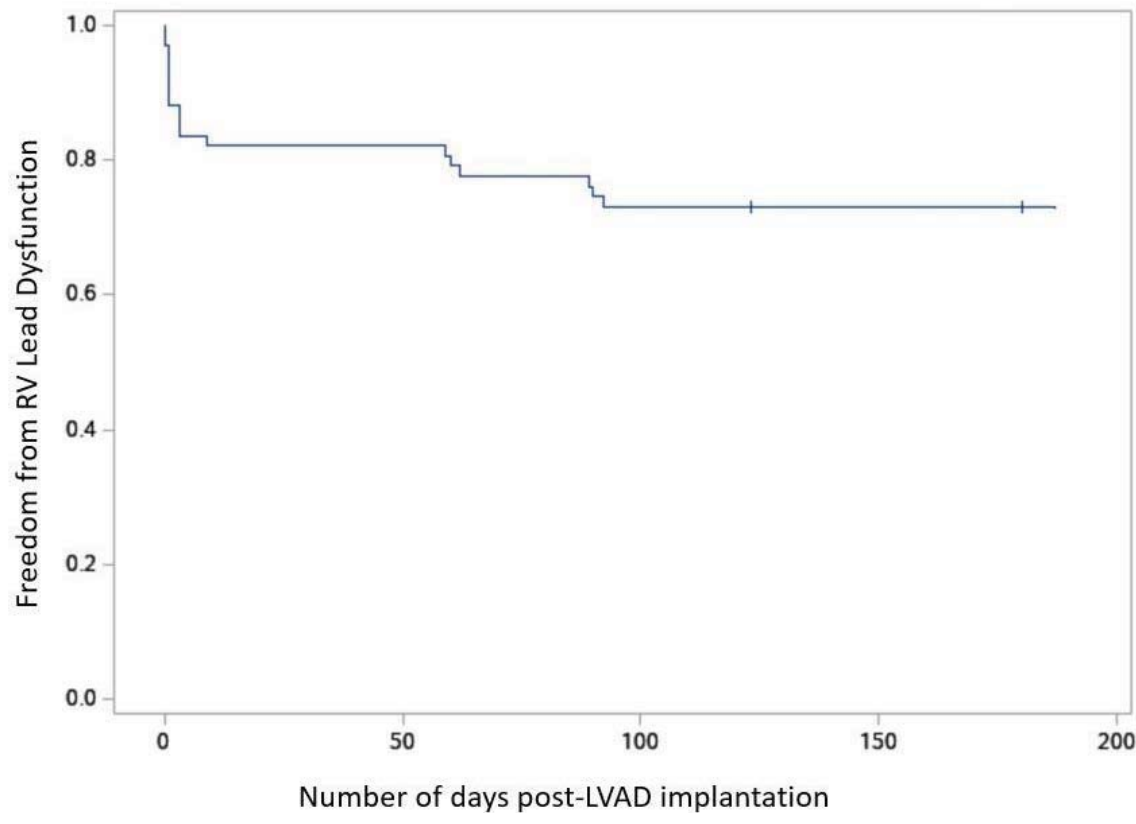

Figure 1. ICD* lead malfunction in first 6 months after LVAD* implant. *ICD: Implantable Cardioverter Defibrillator; LVAD: Left Ventricular Assist Device. different in the RV lead malfunction group compared to the rest of the patients.

Conclusion: There is a high incidence of right ventricular lead dysfunction post implantation of left ventricular assist devices.

https://doi.org/10.32873/unmc.dc.gmerj.2.1.078

\section{Are We Missing Vitamin Deficiencies in Parkinson's Disease?}

Praveen Hariharan ${ }^{1}$, Erin L. Smith², Nabeel M. Syed ${ }^{2}$, Bobbi J. Roeder ${ }^{2}$, Jenna Paseka ${ }^{1}$, Danish Bhatti ${ }^{2}$, Diego R. Torres-Russotto ${ }^{2}$, John M. Bertoni ${ }^{2}$ ${ }^{1}$ University of Nebraska Medical Center, Department of Neurological Sciences

${ }^{2}$ University of Nebraska Medical Center, Department of Neurological Sciences, Division of Movement Disorders

Mentor: John M. Bertoni

Program: Neurological Sciences, Division of Movement Disorders

Type: Case Report

Background: Parkinson's disease (PD) management focuses on quality of life, including adequate nutrition. Extensive literature has correlated nutritional deficiencies and PD, but they are still commonly missed. Many new neurological symptoms are attributed to disease progression without ruling out these treatable conditions.

Methods: We present three cases of PD patients with diverse neurological symptoms whose workup showed reversible vitamin deficiencies.
Results: Case 1 This 81-year-old male physician with PD developed weight loss, irritability, and dementia attributed to advanced disease. Workup revealed low thiamine (B1) of $30 \mathrm{nmol} / \mathrm{L}$ (70-180), pyridoxine (B6) of $5.2 \mathrm{nmol} / \mathrm{L}$ (20.0-125.0), cobalamin (B12) of $72 \mathrm{pg} / \mathrm{mL}(180-914)$, and 25-hydroxyvitamin D of $14 \mathrm{ng} / \mathrm{mL}$ (30-80). He was noncompliant with replacement and passed away. Case 2 This 90-year-old woman 